\title{
Demand in New Zealand Hospitals: Expect the Unexpected?
}

\author{
Nan Jiang \& Gail Pacheco \\ Department of Economics, Auckland University of Technology, Auckland, NZ
}

\section{Draft Paper: not to be quoted without author's permission}

\begin{abstract}
The health care sector in New Zealand has undergone substantial structural reform since 1983, and stands out relative to other OECD countries, in that it has a relatively low per capita health expenditure, and a high share of public funding. Efficient allocation of resources to accommodate local needs in this community-oriented and public dominant model of the health care system is paramount. This paper employs the National Minimum Dataset from 2007 to 2011 to construct an empirical model aimed at predicting hospital demand. We formulate an easy to implement approach that can be used at the national level, as well as for individual District Health Boards (DHBs) that are regionally defined, and can also be disaggregated by category of patient, e.g. acute care versus elective admissions. We find the use of lagged information in this model to be vital, and by contrasting expected and actual demand, we then evaluate variations in excess demand. We find evidence that suggests in low risk elective cases, unexpected demand significantly reduces an individual's hospital stay, and increases the likelihood of acute readmission in 30 days. Additionally, the cumulative evidence presented points to excess demand at both the hospital level and within-disease chapter, resulting in more attention paid to high risk patients, to the detriment of low risk cases. The negatively and significant association between hospital stay and readmission in 30 days for low risk cases may prompt policy makers to consider a 'reduction in readmission program' for New Zealand.
\end{abstract}

Key words: hospital demand, emergency readmission, length of hospital stay, in-hospital death, hospital staffing 


\section{Introduction}

Decisions on hospital staffing levels are often made while trying to carefully balance the need to ensure sufficient personnel for quality care, with an eye on minimising excess costs and operating as efficiently as possible. If too much weight is placed on the cost side of this balancing act, or if the decision making process is flawed in general, then insufficient personnel could result in poorer patient outcomes that include increased length of stay, a greater risk of readmission, and possibly in-hospital death.

In New Zealand (NZ), the health sector has undergone substantial reform since the early 1980s, with the most recent changes in 2000 reflecting a movement from a market oriented model (where separate health entities competed against each other for funding) to a more community focussed approach. It is in the latter that region specific district health boards have been provided greater mandate to deal with local health needs and preferences.

In this paper, we make use of national hospital data for the period of 2007 to 2011 in $\mathrm{NZ}$, and begin by formulating an empirical model aimed at predicting hospital demand. The literature on demand or utilization of hospital capacity is minimal and makes use of varying frameworks. Some of the earliest evidence of research on this front (Feldstein and German, 1965) argued that there are three possible ways to predict future demand (or as the authors termed it 'patient-day/population ratio'). This included (i) using past evidence on demand, (ii) using past evidence on supply / availability of beds, (iii) understanding other factors that may affect use. If demand is relatively predictable, in that hospitals have access to enough information to accurately predict demand levels, then cases of excess demand will be minimal. This is crucial if we assume that excess demand may result in poorer quality care (relative to days without excess demand). Previous research has also shown that the likelihood of readmission is greater when patients experience substandard care (see Ashton et al, 1997; Encinosa and Hellinger, 2008). More recently Morris et al (2011) finds evidence of a positive relationship between hospital-acquired conditions and readmissions.

The data set employed in this study has several advantages for the purposes of our analysis. It is an aggregate source for the country, in that it covers all public hospital admissions across NZ for the sample time frame. There is also detailed information on the individual patients in terms of demographics, their socio-deprivation decile, and other patient record data that is indicative of risk level. Between 2007 and 2011 we find descriptive evidence of a drop in hospital stays for most categories of patients and a corresponding significant rise in acute readmissions. 
We then construct two indicators of volatility in demand to represent shocks to the demand system at the hospital and disease chapter level. The unexpected demand at the hospital level makes use of predicted patient counts and contrasts this with actual patient levels. At the disease chapter level, we attempt to assess times in which a particular disease chapter may have additional strain on hospital resources and capacity, above and beyond the level of volatility at the hospital level. In particular, the following analysis constructs a ratio which contrasts the level of volatility at the disease chapter level, to the level of volatility at the hospital level. We then employ these two unexpected demand indexes in a panel regression framework to estimate the role they play in three patient outcomes: length of stay, risk of readmission within 30 days, and probability of in-hospital death.

Overall, the evidence points to low risk patients having adverse outcomes in times of an unexpected workload - with a shorter hospital stay, and a greater chance of readmission (in elective cases). Unexpected volatility at the disease chapter level (greater than hospital volatility) appears to reduce the length of stay for low risk patients, and actually reduce the probability of readmission for high risk patients. This may be an indicator that in times of stress, staff make high risk patients a priority, and that this may be to the detriment of low risk cases.

The paper proceeds as follows: Section 2 surveys the relevant literature on empirically estimating hospital demand and provides background on the NZ health system. Section 3 details the data employed in this research, as well as descriptive trends over the sample time frame of 2007 to 2011. Section 4 presents a framework for predicting hospital demand, which is flexible enough for the Ministry of Health to employ at the aggregate country level, as well as adapt for specific regional DHBs. This section also outlines the construction of the index to measure when volatility is greater at the disease chapter level relative to the hospital. Section 5 then presents results of assessing the impact of excess demand at the hospital and disease chapter level on adverse outcomes for the patients. In an important extension to the literature, we use one of the outcome variables (excess length of stay in initial hospital admission as a predictor of probability of readmission). Finally, Section 6 presents conclusions and possible policy implications.

\section{Literature Review}

Prior research on gauging hospital demand or understanding the impact of operational failures (the latter being the consequence of failing with the former) are scant. Nevertheless, the importance of this issue has long been recognised in the literature. For instance, Rasmussen (1991) argues that insufficient hospital personnel can affect the ability of nursing services (which 
provide the bulk of patient care within the hospital) to practice according to the legal requirements, resulting in potential threats to patient safety, as well as nurse and hospital liability. The importance of specific staff to patient ratios motivated legislation in California in July 2003, which created mandated minimum patient-to-nurse ratios for this region's hospitals. Analysis of data prior to this legislation by Aiken et al (2002) found that on average each additional patient per nurse was associated with a 7\% increased probability of dying within 30 days of admission. Additionally, the odds of patient mortality also increased (by 7\%) for every additional patient in the average nurse's workload in their sample. The likely contributing factors are higher emotional exhaustion and greater job dissatisfaction, which were both found to be strongly associated with patient-to-nurse ratios. Empirical evidence from Aiken et al (2002) points to an increase of 1 patient per nurse increasing the odds of burnout and job dissatisfaction by $23 \%$ and $15 \%$ respectively.

Legislated minimum ratios for nurses-to-patients is likely to be most effective when applied to hospitals with minimal variation in size, facilities, type, etc. In NZ, there are 20 District Health Boards and within these, 29 major hospital facilities that vary in size, characteristics of patients, demand for services, etc. For example in 2011, the number of hospital episodes per facility varied from just over 5,000 at Bay of Islands hospital, to more than 100,000 at Auckland city hospital. Beside differences in volume, facilities also differ greatly with respect to proportion of hospital episodes that are acute each year, and along with that the average hours in intensive care units (ICUs). For instance, acute events accounted for $65.78 \%$ of hospital episodes at Middlemore hospital (part of Counties Manukau DHB), and 10.44\% at Burwood hospital in the Canterbury DHB. Given these variations, at the facility level, it is likely that mandated levels of nurse to patient ratios that are uniform across NZ are unlikely to be effective. It is also worth noting that recent research by Cook et al (2012) that presents analysis of California's AB394 (mandated minimum nurse staff levels), indicates that failure to rescue rates did not disproportionately increase for hospitals affected by this legislation ${ }^{1}$.

While the literature on understanding hospital utilization is meagre, the framework employed for such analysis is not consistent. Oliveira (2002) uses a flow demand model that represents a system which considers both population points and hospital points, and demand is taken as a concept that relates each population point to a supply location. The author finds several key

\footnotetext{
${ }^{1}$ Cook et al (2012) do find evidence of a significant and positive link between nurse/patient ratios and failure to rescue when viewing it in a cross sectional fashion, but the authors caution that there are difficulties associated with drawing causal inferences from these results.
} 
individual factors that increase the probability of a hospital admission, such as smoking, and weight level. Neighbourhood level effects in terms of socio-economic pockets of poverty were also found to have a positive impact on hospital utilisation.

Recent research by Schwierz et al (2012) on this front measures foreseeable demand as dependent on department and hospital fixed effects, monthly dummies, day of the week dummies and a dummy for public holidays. We contend in the following analysis that practitioners, in addition to the above information, are more flexible in their predictions and also base staffing decisions and allocations on recent information (lagged information regarding demand in the previous week) and trends at the same time in the preceding year. Additionally, our aim in this paper is to create a model that is easy for hospitals to implement should they wish to predict forthcoming utilization rates. We therefore don't include variables that may be difficult for hospitals to measure explicitly or average out for a large region - such as the weather. This factor includes a range of sub-categories such as hours of sunshine, temperature, mm of rainfall, etc. Some components of this factor may be relevant in certain circumstances (e.g. Mastrangelo et al (2007) finds the duration of a heatwave to be a significant influence on hospital admissions), but this variable or set of variables may be too difficult or not readily available for hospitals to average out for large geographical areas that they serve.

How hospitals and particular departments (which we proxy with disease chapters in the following analysis) cope with deviations from foreseeable demand is the focus of this paper, within the context of NZ. There is mixed evidence on this front. For example, Tarnow-Mordi et al (2000) use UK data over the period 1992 to 1995 and links increased probability of death with greater than average patients in the intensive care unit. Evans and Kim (2006) use hospital discharge data for California over the period 1996 to 2000 to estimate the impact of a substantial influx in patients on the following two days. Focussing on patients admitted Thursday, they find some evidence of demand shocks on Friday and Saturday reducing the length of stay for Thursday admissions, and their probability of readmission. While their results are statistically significant, the authors caution the reader to the fact that the impacts are quantitatively small. Recent research by Schwierz et al (2012) also examines the impact of excess demand on patient outcomes, with a focus on acute care hospitals in Germany in 2004. They find hospitals are relatively well prepared to deal with unexpected volatility in demand, and that there is minimal impact on patient outcomes. We begin our empirical analysis by employing a similar approach to 
Schwierz and colleagues with respect to estimating foreseeable demand, but first detail the institutional background for the case of NZ and the unique data set at our disposal.

\section{NZ background}

Since the 1980s, NZ's health system has undergone a series of radical reforms. In all, there have been three major restructures to the health system in the last three decades, along with a myriad of smaller structural shifts that have altered the way in which health services are funded, organised and delivered. In 1983 legislation was passed to create Area Health Boards (AHBs), and there was a move to population-based funding for hospital care (previously funding was based on historical allocations and further negotiated additions) (Pool et al, 2009). In 1993, a 'purchaser/provider' market-oriented model was introduced (Ministry of Health, 2012), and four regional health authorities were formed to 'purchase' health care from a range of providers, to produce health gains for the populations of their respective regions. This competitive internal market system was theoretically expected to result in greater efficiency, and in practice resulted in geographically separate health entities heavily competing on the health market, developing independent process and structures, and substantially reducing the level of coordination and collaboration across regions. In 2000, NZ moved from this market-oriented model to a more community-oriented approach. Via implementation of the New Zealand Public Health and Disability Act in 2000, 21 district health boards (DHBs) were created, with a mandate to cover primary and other health sectors (Gauld, 2009). The creation of the DHB structure resulted in the decentralisation of planning and funding functions to the local level, such that DHBs are given direct responsibility for their respective communities. The motivation for this being that decision making at the local level enhances close ties with the community, and greater / quicker reaction to community needs and preferences in the health market. There are now 20 DHBs (Southland and Otago DHBs merged in May 2009) that are responsible for the provision of health and disability services in their geographic area.

\section{Data}

The National Minimum Dataset (NMDS) is a unit record national collection of public and private hospital discharge information, for inpatients and day patients who are formally admitted to an institution for treatment in NZ. Across our sample period of 1 Jan 2007 to 31 Dec 2011, the NMDS contains 4,953,049 hospital events. The majority of events are acute admissions $(51.23 \%)$, followed by arranged $(28.18 \%)$ and waiting list admissions (20.58\%). An acute 
admission is defined as an unplanned admission on the day of presentation, where as an arranged admission is a planned admission where the admission date is less than 7 days after the admission decision was made by the specialist. The final category of waiting list admissions are also described as planned admissions, but the admission date is 7 or more days after the specialist's decision. In the following analysis, we group together waitlist and arranged into a category denoted as 'elective'. Rare events, such as elective admission of a privately funded patient (87 events over 5 years) or, psychiatric patient returned from leave of more than 10 days (137 events), were dropped from the forthcoming analysis.

Given that around three quarters of the health funding and most of the day-to-day business in the health system is administered by the 20 regional district health boards (DHBs) in NZ, our attention is further confined to hospital events at the DHB level $(95.69 \%)$. As a consequence to this decision, events delivered by private health groups $(3.79 \%)$, trust or incorporated society $(0.51 \%)$ and other publicly funded agencies $(0.02 \%)$, were excluded from our final data sample. These exclusions left us with a sample of 4,739,435 events. Our next step was to remove observations that have the potential to distort average effects of demand on patient outcomes. Therefore, individuals below the age of 18 at discharge (21.04\%) and above the age of 75 $(16.57 \%)$ are also dropped from our final sample. The first group has a very low probability of adverse health outcomes (total in-hospital mortality rate of $0.15 \%$ ) and the second group has a higher than average mortality rate $(3.60 \%)$, that is likely not to be linked to the quality of hospital care. Finally, given the focus of our study, we also exclude psychiatric inpatient events $(6.16 \%)$, birth events $(1.12 \%)$, and events with a discharge reason other than regularly ended or death (i.e. transfer discharge, self-discharge etc. 8.67\%). The final sample size is 2,699,453 hospital events, across five years, and 20 DHBs (See Appendix 1 for a distribution of events by DHBs and a description of context relevant facts regarding each DHB area - such as population size, ratio of urban to rural, and proportion above median income). This sample corresponds to $1,005,482$ unique patients.

This data set is well suited to the purpose of this study and has a number of advantages relative to data used in prior relevant international empirical studies. For instance, this sample allows analysis of distinct regions across NZ, based on DHB level. Secondly, investigation of patterns in expected and unexpected hospital demand over time are enabled given the availability of data from 2007 to 2011. Variations across regions and time are valuable extensions to the literature in this field. Schwierz et al (2012) focussed on one region in Germany and for the year 2004, 
Dobkin (2003) also focus on one region in the United States (California) for the period of 1995 to 1999. Most importantly, having an aggregate source of hospital admissions for the whole country makes it easy to make inferences as to what is the most appropriate model hospitals could use to predict demand - i.e. generating a 'one size fits all' model that would be easy for hospitals to implement, as well as disaggregating this predictive analysis by region or by type of patient, e.g. acute versus elective admissions.

The NMDS contains relevant information regarding patient characteritiscs (such as age, gender, and ethnicity), individual risk factors (such as clinical complexity level, hours on medical ventilation, etc.) and patient outcomes (death within hospital, excess length of stay relative to the average length by diagnoses, and emergency readmission). The descriptive statistics of the sample and definitions of the relevant outcome variables, as well as covariates, are provided in Table 1.

Following Evans and Kim (2006) and Schwierz et al (2012) we also divide the sample along the lines of low versus high risk. This is done at the aggregate level, as well as for the sub-categories of acute, planned, and wait list admissions. We expect a priori that the high risk category are more susceptible to adverse health outcomes. A patient is regarded as high risk if their primary diagnosis belongs to one of the 50 diseases with the highest mortality rate among all causes with at least 40 deaths in the data.

In general, low risk patients appear to be more likely to be younger, female, and non-European, relative to individuals in the high risk category. As expected risk factors such as the clinical complexity level are lower for low risk individuals. Additionally, with respect to patient outcomes, low risk patients are clearly less likely to exceed the average length of stay based on their diagnoses; die in hospital; or require an acute readmission within 30 days of discharge.

While Table 1 presents means and standard deviations of the aggregate sample for NZ over the period of 2007 to 2011, we have also conducted descriptive analysis for each year separately and then used t-tests to ascertain whether the means have increased / decreased, or remained static over the sample period. The results of these test are denoted with 'Up'; 'Down'; or '-' to signify a significant increase; decrease; or no significant change between 2007 and 2011. For instance, the average age increased for most categories in Table 1. In terms of ethnicity, Maori and Pacific Peoples are increasingly represented in both low and high risk admissions. 
The most interesting trends over the sample period are in terms of patient outcomes. Between 2007 and 2011, excess length of stay decreased across almost all categories in Table 1, bar arranged and wait list high risk (where there was no significant change). This is an indication that hospitals are increasingly likely to promote patient discharge as soon as feasible. A decrease in excess length of stay may also be a result of capacity constraints (Sharma et al, 2008). The likelihood of in hospital death has also decreased over the sample period, which is expected given the regular advances in medical science. Unfortunately it is worrying that in every category in Table 1 the likelihood of acute readmission in the 30 days following discharge significantly increased over the sample period. Coupled with the trends in excess length of stay, is this a sign that NZ hospitals are pushing patients out the door too early? Are these outcomes influenced by unexpected demand and consequently insufficient quality hospital care? For instance, previous work by Heggestad (2002) for Norway finds a positive association between average length of stay and staffing ratio, with respect to elderly patients' (at least 67 years or age) risk of readmission. In the next section we focus on predicting demand at both the aggregate country level in NZ, as well as regional sub-groups based on specific DHBs, to ascertain whether hospitals have access to enough information to be able to accurately predict expected demand levels.

\section{$<$ Insert Table 1 about here $>$}

\section{Empirical analysis}

\subsection{Demand}

Given the high share of public funding in NZ in the health care sector (approximately $83.2 \%$ of total health spending in 2010), efficient allocation of public resources are paramount. This involves having sufficient personnel and infrastructural capacity at local hospitals and therefore being able to make reasonable predictions regarding hospital demand. Cyclical and seasonal patterns in hospital demand are common and therefore being able to accurately predict forthcoming variations in demand can aid in budget allocations, and deciding on appropriate staffing levels. In times of unexpected demand, hospitals may fail to deliver a high and consistent standard of care. This may result in negative patient outcomes, in terms of a greater length of hospital stay (further strain on public finances), a higher risk of emergency readmission, and at worse, death. 
The first step in assessing the impact of demand variation of patient outcomes is to construct foreseeable demand. Empirical studies that investigate hospital demand are sparse (see Schwierz et al (2012), Oliveira (2002) and (2004), and Dove \& Ritchie (1972)) and often do not specifically account for previous demand levels. We expect that staffing levels in hospitals are planned based on the following factors: (i) demand during the same time in the previous year, (ii) seasonal patterns, (iii) public holidays and weekends, and (iv) recent regional upsurge or spread of disease. These factors are expected to result in variations in hospital demand that are foreseeable to hospital management, and therefore should not affect the quality of healthcare if fully captured in planning decisions ${ }^{2}$.

To ascertain predicted hospital demand at the aggregate country level, as well as for yearly and regional DHB sub-samples, we ran a regression of patient counts for hospital $b$ within DHB $d$ on day $t$. We employed the following covariates in our fixed effects regression analysis: monthly dummies; day of the week dummies; a dummy for public holidays; patient count in the previous 6 days; and patient counts in the last 361-366 days.

$P_{h t}=\beta_{0}+\boldsymbol{\alpha} \boldsymbol{M}_{t}+\boldsymbol{\gamma} \boldsymbol{D}_{t}+\beta_{1} h_{t}+\beta_{2} P_{h t-1}+\cdots+\beta_{7} P_{h t-6}+\beta_{8} P_{h t-361}+\cdots+\beta_{13} P_{h t-366}+u_{h t}$

where

$P_{h t}=$ Patient counts at hospital $b$ on day $t$

$\boldsymbol{M}_{t}=$ a set of dummies for each month from February to December, with January being the reference

$\boldsymbol{D}_{t}=$ a set of dummies for Tuesday, Wednesday,..., and Sunday, with Monday being the reference

$h_{t}=$ a dummy variable for public holiday

$P_{h t-1}=$ Patient counts at hospital $h$ on the previous day

$P_{h t-6}=$ Patient counts at hospital $b 6$ days before

$P_{h t-361}=$ Patient counts at hospital $h 361$ days before

$P_{h t-366}=$ Patient counts at hospital $h 366$ days before

$u_{h t}$ is a random error

It is the last two variables that prove to be crucial in predicting hospital demand, and oddly absent from relevant past models predicting hospital demand (e.g. Schwierz et al, 2012 for Germany; and Oliveira, 2002). To illustrate the importance of these two lag variables (demand in the preceding week, and demand in the comparable week a year earlier), Table 2 reports the goodness of fit measure ( $\mathrm{R}$ squared) for the predicted demand regression across DHB subsamples, and where appropriate, across facilities within the same DHB.

$<$ Insert Table 2 about here $>$

2 This ofcourse assumes there are no supply constraints with respect to appropriate personnel. 
As shown in Table 2, inclusion of the lag indicators in the fixed effects regression predicting hospital demand is paramount. Regardless of the ability of DHBs to predict hospital demand (proxied by the $\mathrm{R}$ squared in the predicted models), which varies both across and within DHB level, adding the two lag variables to the model substantially increases the goodness of fit measure. For instance, across the facilities in the Bay of Plenty region, the $\mathrm{R}$ squared for the predicted hospital demand equation ranged from 0.075 to 0.148 . However, after the inclusion of the lag variables, the explained variance increased to between 72.4 and 73.4 per cent. Similar patterns are exhibited in the remaining DHBs. Interestingly, it appears that it is the most difficult to predict hospital demand in Northland. The R squared for the model relating to Bay of Islands (one of the three major facilities in Northland) was a low 0.021 prior to the inclusion of lags, and this increased to 0.325 after lags were added to the covariate list. This finding is easy to explain, as the Bay of Islands serves a geographically dispersed population and is a popular tourist destination. The latter of these reasons, indicates that while the predicted model fits well for most regions across NZ, it may need to be adapted for Northland with relevant tourist information, such as volume and country of origin.

Regression results are not reported for brevity sake, but can be obtained from author upon request. Given that it is the unforeseeable (unexpected) variation in demand that may impact quality of care and lead to adverse patient outcomes, we next make use of the daily predicted expected patient counts and contrast these with actual patient counts. Unexpected demand is measured as the ratio of predicted to actual. The actual patient counts and unexpected patient counts are centred on 1, and their values reflect the percentage difference between yearly mean demand and daily demand. From the whole sample period results (Panel A in Table 3), we can see that, on $10 \%$ of the admission days between $2007-2011$, actual demand is $79 \%$ of mean demand. On another $10 \%$ of the days, actual demand is at least $119.9 \%$ above mean demand.

\section{$<$ Insert Table 3 about here $>$}

With respect to unexpected demand, Panel A indicates that for the full sample, on $20 \%$ of days (the $10^{\text {th }}$ and $90^{\text {th }}$ percentile) admissions are approximately $12 \%$ higher or $13 \%$ lower than expected. Further variation is illustrated if viewing the $5^{\text {th }}$ and $95^{\text {th }}$ percentiles, which indicates that on $10 \%$ of days, admissions are just under $20 \%$ higher or lower than expected. Similar figures for Germany (and in particular the North-Rhine Westphalia region) by Schwierz et al (2012) indicate that in comparison, there is potentially less variation in unexpected demand for 
NZ hospitals. They find that unexpected demand on $10 \%$ of days $\left(5^{\text {th }}\right.$ and $95^{\text {th }}$ percentile) is nearly 30\% away from expected demand. Interestingly, further analysis proves this difference is not necessarily a result of differences in volatility of demand between NZ and Germany - in particular, the main difference between Schwierz et al (2012)'s analysis and this analysis, is that we explicitly control for demand levels in the previous year and preceding week, via two lag indicators. If instead we don't assume that this information is used to inform predictions regarding expected hospital demand (i.e. don't include lags in our analysis of expected demand), then we find similar index values (relative to Schwierz et al (2012)) for unexpected demand at the $5^{\text {th }}$ and $95^{\text {th }}$ percentile (specifically 0.72 and 1.29$)$.

Nevertheless our analysis clearly points to volatility in unexpected hospital demand, and it is important to note that it is not skewed in either a positive or negative direction. The results across time (Panel C) illustrate that unexpected demand has remained relatively stable over the period 2008 to 2011 . The findings described above with respect to $10 \%$ of admission days, and $20 \%$ of admission days hold across each of the yearly sub-samples.

At the DHB level (Panel B), results show that Mid Central and West Coast DHBs experienced relatively volatile demand. In particular, on $10 \%$ of days, admissions were approximately $39.8 \%$ lower or $56.5 \%$ higher than expected levels of demand for the Mid Central DHB. Comparable figures for West Coast DHB were 23.1\% lower and 31.4\% higher. The West Coast statistics are easy to comprehend, in that it is the smallest DHB in our analysis - Appendix 1 illustrates that it has the least events in our sample, and comprises just $0.65 \%$ of the data set. Predicting hospital demand in a smaller region is much more problematic, as small shifts in demand in absolute terms can appear to be large shifts proportional to expected patient numbers. The same cannot be said for Mid Central, which has more than five times the number of hospital events relative to the West Coast, and accounts for just under $4 \%$ of the data set. However, on closer inspection, Mid Central DHB has one major facility - Palmerston North hospital, and given this is university town, tertiary students play a major role in population fluctuations in this region and potentially volatility in demand. Delving further into hospital admission trends for this DHB we find patient counts at Palmerston North hospital usually peak in July and December each year - the time period immediately following exam weeks in the university academic calendar.

In terms of which regions have minimal differences between actual and expected demand, Auckland, Waikato, and Hutt Valley DHBs stand out as the only three regional sub-samples 
where the 95th percentile for the index of unexpected demand is less than 1.1, indicating that on $5 \%$ of admission days, actual demand doesn't deviate further than $10 \%$ above expectations. Furthermore, in all three DHBs, the 5 th percentile is above 0.9 , indicating that on another $5 \%$ of admission days, actual demand doesn't deviate further than 10\% below expected demand. It appears that unexpected demand levels are not related to economies of scale, as all three cases of low volatility in deviations from expectations range in size from just 80,000 events across the sample period for Hutt Valley, to more than 300,000 events for Auckland.

\subsection{Unexpected demand within disease chapter}

We next construct an index to capture unexpected demand at the disease chapter level. This is an important construct to control for in the following regressions, as it captures volatility at a more disaggregated level, than just the aggregate hospital level. It is easy to motivate if we imagine that if the hospital on average is under pressure in terms of capacity, there may not necessarily be an impact on all areas of the hospital. Conversely, if a certain department or area of specialisation within the hospital is under more strain relative to the volatility in hospital demand, there may be an additional impact on patient outcomes. To capture this possible incremental impact that might result from increased pressure at the department level, we use as a proxy within-disease chapter volatility in demand ${ }^{3}$. Disease chapters are classified under the ICD-10 codes of primary diagnosis. For example, hospital admissions with primary diagnosis codes of A00-B99 fall into chapter I: certain infectious and parasitic diseases; C00-D48 = chapter II: neoplasms, and so on ${ }^{4}$. We focus on disease chapters, rather than individual level diagnosis information as the latter results in small sample sizes. For instance, Chapter XI encompasses diseases of the digestive system, including disorders of tooth development, inflammatory conditions of jaws and disturbances of salivary glands etc. More specifically, Chapter XI includes 427 different specific diagnosis codes in this dataset, some of which only occur once or twice in the entire sample period (e.g. fistula of the appendix). If we control for the difference in variation of excess demand relating to a specific diagnosis relative to variation in excess demand at the hospital level, this could mean a lot of weight is placed on the basis of small number of cases, and this could therefore bias our estimates of the impact of unexpected demand at the diagnosis level. Schwierz et al (2012) go down this route, of assessing variation in demand at the diagnosis level, and their rational is that such variation at this lowest level of disaggregation captures unobservable risk.

\footnotetext{
${ }^{3}$ Unfortunately our dataset does not include information on department categories.

4 See World Health Organisation (2013) for a full list of the 22 disease chapters (found at http://apps.who.int/classifications/icd10/browse/2010/en).
} 
This is because they expect that demand at the patient diagnosis level will match the variation in excess demand at the hospital level, and that if it doesn't, that this is an indicator of unobservable severity of case. In contrast to their study, we contend that risk can be captured by our segregation of analysis into low and high risk categories. As described in section 2, a patient is assumed to be high risk if their primary diagnosis belongs to one of the 50 diseases with the highest mortality rate among all causes with at least 40 deaths in the data. Additionally, by focussing on within-disease chapter volatility in demand we are more interested in the incremental effect of additional volatility in demand (above and beyond excess demand at the hospital level) within certain areas of the hospital or specific departments.

We therefore construct an 'unexpected disease-chapter demand' index in the following fashion: for each disease chapter $j$ within hospital $h$, we calculate a ratio of the number of admissions on days with excess demand (i.e. a day where predicted patient count is less than the actual patient count), relative to the total admissions for that particular disease chapter. This is denoted $r_{j h}$. Then for each hospital h, we measure the ratio of the number of days with excess demand, relative to the total days. This is denoted $r_{h}$. If the volatility in demand at the disease chapter level is equivalent to that at the hospital level, then we would expect $r_{h}=r_{j h}$ for each $j$. If the difference $u_{j h}=r_{j h}-r_{h}>0$ then there are excess admissions in disease chapter $j$ on days with excess demand in hospital $h$. This is indication of excess strain on resources at the diseasechapter level, over and above the pressure on the hospital resources in general. Table 4 presents the descriptive statistics for the whole sample in terms of $u_{j h}$, as well as the two DHBs that show the least and most variation in this index ${ }^{5}$.

$<$ Insert Table 4 about here $>$

It is apparent that admissions on the basis of disease chapter are not evenly distributed across the days in which the hospital experiences excess demand. In particular, for the whole sample, for $5 \%$ of events, there are $0.03 \%$ less admissions per disease chapter on days of excess demand at hospital level; and for another 5\% of cases, there are 14.8\% more admissions per disease chapter on days of excess demand at the hospital level. The top end of this distribution spectrum indicates substantial unevenness wihen comparing volatility in demand between the hospital and disease chapter level. Furthermore, the importance of regional analysis is emphasized here, as sub-group analysis by DHB reveals ranging variation in $u_{j h}$ across regions of NZ. For instance,

\footnotetext{
${ }^{5}$ In the interest of space saving, we have not presented the results for all 20 DHBs, but these can be obtained from the author upon request.
} 
in Auckland, we can infer from the $95^{\text {th }}$ percentile of this index that for $5 \%$ of events, there are just over 4\% more admissions per disease chapter on days of excess hospital demand. The comparable figure for Capital and Coast is $27.1 \%$, indicating the need to control for this factor when modelling patient outcomes.

\subsection{Patient outcomes}

We next assess the impact of unexpected demand at both the hospital and disease chapter level on patient outcomes, with a focus on three negative outcomes: excess length of stay, acute readmission, and in-hospital death. We employ a panel regression model for patient $i$ with illness / diagnosis $j$ in hospital $h$ at day $t$.

$$
\begin{gathered}
Y_{i j h t}=\delta_{0}+\delta_{1} D_{h t}+\delta_{2} R_{j h}+\boldsymbol{\varepsilon} \boldsymbol{X}_{i j h t}+\boldsymbol{\theta} T_{t}+\boldsymbol{\tau} \boldsymbol{H}_{h}+w_{i j h t} \\
A_{i j h t}=\delta_{0}+\delta_{1} D_{h t}+\delta_{2} R_{j h}+\delta_{3} Y_{i j h t}+\boldsymbol{\varepsilon} \boldsymbol{X}_{i j h t}+\boldsymbol{\theta} \boldsymbol{T}_{t}+\boldsymbol{\tau} \boldsymbol{H}_{h}+v_{i j h t} \\
M_{i j h t}=\delta_{0}+\delta_{1} D_{h t}+\delta_{2} R_{j h}+\delta_{3} Y_{i j h t}+\boldsymbol{\varepsilon} \boldsymbol{X}_{i j h t}+\boldsymbol{\theta} \boldsymbol{T}_{t}+\boldsymbol{\tau} \boldsymbol{H}_{h}+q_{i j h t}
\end{gathered}
$$

where

$Y_{i j h t}=$ is the excess length of stay for patient $i$ with illness $j$ in hospital $b$ at day $t$

$A_{i j h t}=$ is a dummy indicating whether patient $i$ with illness $j$ in hospital $h$ on day $t$ is having an acute readmission within the next 30 days following discharge, conditional on the survival of the current admission

$M_{i j h t}=$ is a dummy indicating in-hospital mortality

$D_{h t}=$ is the excess demand at day $t$ in hospital $b$

$U_{j h}=$ is the excess demand at disease chapter level, above the level of hospital demand volatility, for illness $j$ in hospital $h$, capturing within-disease chapter strain on resources and capacity.

$\boldsymbol{X}_{i j h t}=$ is a vector of patient' characteristics: male; dummies for patients aged 30-39, 40-49, 5059, 60-69 and 70-79 and interactions between male and age groups; the cost weight; dummies for patient clinical complexity level; whether the admission was operative, the number of secondary diagnoses; and the hours on mechanical ventilation. We also include a set of deprivation index dummies capturing the social-economic status of the patients.

$\boldsymbol{T}_{t}=$ a vector of dummies denoting the days of the week (Tuesday to Sunday) and months of the year (February to December), and whether the day is public holiday

$\boldsymbol{H}_{t}=$ a vector of dummies for each hospital, with Middlemore hospital being the reference group.

$w_{i j h t}, v_{i j h t}, q_{i j h t}$ are random errors 


\section{Results}

Table 5 provides results of the regressions outlined in section 4.3. All covariates listed above are included in the specification, but not reported for the sake of brevity. In general, we find older males, patients who live in a more deprived region, have an operative admission, and increasing number of secondary diagnoses, more likely to have a longer hospital stay. In terms of our key variables, we report the estimated coefficients on unexpected demand at the hospital level, and the incremental impact of unexpected demand within disease chapter in Panel A, where the outcome is excess length of stay. As unexpected demand at the hospital level increases, it reduces the length of hospital stay for low risk elective admissions (significant at the $1 \%$ level). Importantly, the added effect for volatility at the disease chapter level, is significantly reduced hospital stays. The estimated coefficients point to low risk patients (whether elective or acute) experiencing these significantly reduced time in the hospital, as a result of additional pressure within-disease chapter, above and beyond the impact of excess demand for the hospital as a whole. We speculate that when staff and capacity are under pressure at both hospital and disease chapter level, the emphasis shifts from low risk patients.

In terms of results within Panel $\mathrm{B}$, where the outcome is probability of readmission within 30 days, we find evidence of excess demand for hospitals triggering an increased chance of readmission for low risk elective patients. This corresponds to the significant impact found on excess length of stay for the same sub-group of patients. Additionally, in an extension to the literature, we include excess length of stay as a covariate in the regressions presented in Panel B, and find for the case of low risk elective patients, a reduced hospital stay significantly increases the chance of readmission within 30 days, significant at the 1\% level (albeit the estimated marginal effect is small).

If in-hospital stay increases, the probability of acute readmission increases significantly for low risk acute admissions. To understand this effect, in conjunction with the reverse impact for low risk elective admissions - we hypothesize that these results may be driven by the fact that in times of high demand, elective patients are discharged earlier than appropriate for them, to make room for acute admissions.

There is one more key result that is worthy of further discussion. Specifically, we find that unexpected demand at the disease chapter level has a positive impact on risk of readmission, for high risk cases (be it elective or acute high risk). This is at odds with initial expectations, that increased volatility in demand may reduce quality of care, and result in potential adverse 
outcomes for patients, such as a higher probability of readmission in 30 days. The fact that this outcome is isolated to high risk cases, and coupled with earlier evidence of significantly reduced hospital stays predominantly for low risk cases, may be indicative that in times of demand pressure, hospital staff shift their emphasis from low risk to high risk patients.

In general, the estimates in the final panel of Table 5 corroborates the picture portrayed above. For instance, unexpected demand within the disease chapter increases probability of in-hospital death for low risk cases (both elective and acute) and decreases the probability for high risk cases. Again indicating that at times of high pressure, hospitals deal with it by prioritising high risk cases, to the detriment of low risk patients. Results for probability of in-hospital death for high risk acute admissions are not presented, as the probit didn't converge, most likely due to small sample size.

\section{Conclusions}

In this study, we have put forth an empirical model to predict hospital demand across the NZ health sector. The predicted patient count model would be easy to implement and could be adapted to specific regional DHBs if necessary. There was some evidence that the region of Northland, and more specifically, Bay of Islands (a tourist area) may require additional information on tourist flow to aid in predicting demand, beyond the current model proposed. In an extension to the literature, we found two sets of lag variables to be imperative in vastly improving model fit criteria in our prediction regressions. Firstly, lags that encompass patient counts in the past 6 days; and second to this, lags that capture patient counts in the corresponding week a year earlier. The former of these sets of variables is easy to motivate, as it may be reflecting recent regional upsurge or spread of disease. A prediction framework is new to the NZ health literature, and can offer policy makers a wealth of useful information. In general, the framework provides greater understanding of which regional DHBs are subject to less foreseeable demand, compared to other regions, and further region specific research could pursue reasons why this may be the case.

We employed an aggregate data source based on all hospital admissions across the NZ public health sector, which resulted in more than 2.6 million cases across a 5 year time frame. We also control for hospital specific factors by focusing on within-hospital differences, and in terms of patient outcomes, segregate our sample across the lines of elective versus acute, and low versus high risk. While the key focus of our study is ascertaining the impact on patient outcomes when 
there is unexpected pressure on NZ hospitals, we go a step further to assess the incremental impact of extra pressure on departments, when hospital resources on average are already strained. Unfortunately, our dataset does not contain department specific information, but we use as a proxy data on variation in demand within disease chapters.

We find evidence that unexpected hospital demand has significant impacts on low risk cases, in that their hospital stay is cut short, and they have an increased probability of readmission within 30 days. This is in contrast to the findings of Schwierz et al (2012), who focus on acute care German hospitals. In extensions to the literature, we add to our patient outcome models, unexpected demand at the disease chapter level, and for the outcome of readmission in 30 days, we also add excess length of stay as a covariate. Our results portray an unexpected, but plausible picture. Unexpected demand at disease chapter level appears to have adverse effects on length of stay and risk of readmission for predominantly low risk cases, whereas this added pressure within the department, seems to benefit the high risk patients. The main lesson here is that when there is unexpected pressure, staff prioritise high risk cases, to the detriment of patients that are deemed low risk. In particular, these low risk patients (especially elective admissions) have significantly shorter hospital stays, greater chance of readmission in 30 days, and increased likelihood of in-hospital death (albeit the marginal effect of this last impact is small).

Our descriptive evidence also showed that regardless of category of patient, excess length of stay has significantly reduced over the sample time frame, and probability of readmission has increased. Our regression analysis confirms there is a significant relationship between these two outcome variables, with respect to low risk elective cases. It would be a worrying sign if this trend continued and may warrant policymakers to consider recent legislation in the United States (U.S.) aimed at reducing readmission rates. Specifically, the Patient Protection and Affordable Care Act of 2010 is just over half way through its four year implementation plan in the U.S., where the main focus is near universal health coverage. Section 3025 of this plan (the Hospital Readmissions Reduction Program) has created a heated debate. Under this program, the Centers for Medicaid and Medicare Services began reducing payments to hospitals with excessive readmissions of patients in October 2012 in certain circumstances. For instance, the focus currently is on heart failure, myocardial infarction, and pneumonia, and hospitals are penalized when readmission within 30 days for these illnesses is higher than the expected for the hospital's particular case mix. The aim of this legislation is to encourage more quality care, with the penalty being loss in terms of Medicare funding. Increasing readmission rates is also a growing problem 
in Europe, and the European Commission and Organisation for Economic Co-operation and Development's Health at a Glance have raised concerns regarding premature discharge of patients. In the United Kingdom, there was a 50\% rise in readmissions between 1999 and 2010 (The Burrill Report, 2013), and as a consequence the Department of Health introduced (in April 2011) a new policy of non-payment for acute hospital readmissions within 30 days of a previous planned hospital stay (subject to a specific set of exclusions). While more research is needed within the NZ context, before we are at the stage where it's necessary for policy makers to consider a readmission for reduction program here, recent research by Gerhardt et al (2013) has pointed to readmission rates falling in the U.S. in 2012, after five years of consecutive increases.

\section{References}

Aiken, L., Clarke, S., Sloane, D., Sochalski, J. and Silber, J. (2002). Hospital nurse staffing and patient mortality, nurse burnout, and job dissatisfaction. Journal of the American Medical Association, 288(16), 1987-1993.

Ashton, C.M., DelJunco, D.J., Souchek, J., Wray, N.P. and Mansyur, C.L. (1997). The association between the quality of inpatient care and early readmission: a meta-analysis of the evidence. Medical Care, 35(10), 1044-1059.

Cook, A., Gaynore, M., Stephens, M., Taylor, L. (2012). The effect of a hospital nurse staffing mandate on patient health outcomes: Evidence from California's minimum staffing regulation. Journal of Health Economics, 31(2): 340-348.

Dobkin, C. (2003). Hospital Staffing and Patient Mortality. Working Paper, Department of Economics, University of California, Berkeley. Available at: people.ucsc.edu/ cdobkin/Papers/Staffing_and_Mortality.pdf

Dove, H. \& Ritchie, C. (1972). Predicting Hospital Admissions by State. Inquiry, 9(3): 51-56.

Encinosa, W. and Hellinger, F. (2008). The Impact of Medical Errors on 90-Day Costs and Outcomes: An Examination of Surgical Patients. Health Services Research, 43(6): 2067-2085.

Evans, W.N. and B. Kim (2006), Patient Outcomes when Hospitals Experience a Surge in Admissions, Journal of Health Economics 25: 365-388.

Feldstein, P.J. and German, J.J. (1965). Predicting hospital utilization: an evaluation of three approaches. Inquiry, 2(1), 13-36.

Gauld, R. (2009). Revolving Doors: New Zealand's Health Reforms - The Continuing Saga (2nd ed.). Wellington, New Zealand: Institute of Policy Studies and Health Services Research Centre, Victoria University of Wellington. 
Gerhardt, G., Yemane, A., Hickman, P., Oeschlaeger, A., Rollins, E., and N. Brennan (2013). Medicare Readmission Rates Showed Meaningful Decline in 2012. Medicare \& Medicaid Research Review, 3(2): E1-E11.

Heggestad, T. (2002). Do hospital length of stay and staffing ratio affect elderly patients' risk of readmission? A nation-wide study of Norwegian hospitals. Health Services Research 37(3): 647-665.

Mastrangelo, G., Fedeli, U., Visentin, C., Milan, G., Fadda, E. and Spolaore, P. (2007). Pattern and determinants of hospitalization during heat waves: an ecologic study. BioMed Central Public Health, 7(200), doi:10.1186/1471-2458-7-200

Ministry of Health (2012). Health Expenditure Trends in New Zealand 2000-2010, Wellington, Ministry of Health.

Morris, D., Rohrbach, J., Rogers, M., Sundaram, L., Sonnad, S., Pascual, J., Sarani, B., Reilly, P., and C. Sims (2011). The Surgical Revolving Door: Risk Factors for Hospital Readmission. Journal of Surgical Research, 170(2):297-301.

Pool, I., Baxendine, S., Cheung, J., Coombs, N., Jackson, G., Dharmalingam, A.,..., and Copper, J. (2009). Restructuring and Hospital Care: Sub-National Trends, Differentials, and their Impacts; New Zealand from 1981 (Monograph; The Population Studies Centre). Retrived from University of Waikato, National Institute of Demographic and Economic Analysis Website: http://www.waikato.ac.nz/nidea/research/hospital-care-monograph

Oliveira, M.D. (2002). A flow demand model to predict hospital utilization. London: The London School of Economics and Political Science.

Oliveira, M.D. (2004). Modelling demand and supply influences on utilization: A flow demand model to predict hospital utilization at the small area level. Applied Economics, 36(20), $2237-2251$

Rasmussen, C. (1991-1992). Hospital Liability Related to Understaffing of Nursing Services: Walking the Fine Line Between Respondeat Superior and Corporate Negligence. West Virgina Law Review.

Schwierz, C., Augurzky, B., Focke, A. and Wasem, J. (2012). Demand, selection and patient outcomes in German acute care hospitals. Health Economics, 21(3), 209-221.

Tarnow-Mordi, W.O., Hau, C., Warden, A. and Shearer, A.J. (2000). Hospital mortality in relation to staff workload: a 4-year study in an adult intensive-care unit. The Lancet, 356(9225), 185-189.

The Burrill Report (2013). Hospital Readmission in Europe. Retrieved from http://www.burrillreport.com/article-readmission_rates_in_europe.html

World Health Organisation (2013). Retrieved from

http://apps.who.int/classifications/icd10/browse/2010/en). 
Table 1: Definitions and descriptive statistics for sample: 2007-2011

\begin{tabular}{|c|c|c|c|c|c|c|c|c|c|}
\hline & Definition & Low risk & High risk & $\begin{array}{l}\text { Acute low } \\
\text { risk }\end{array}$ & $\begin{array}{l}\text { Acute high } \\
\text { risk }\end{array}$ & $\begin{array}{l}\text { Arranged } \\
\text { low risk }\end{array}$ & $\begin{array}{l}\text { Arranged } \\
\text { high risk }\end{array}$ & $\begin{array}{l}\text { Wait list low } \\
\text { risk }\end{array}$ & $\begin{array}{l}\text { Wait list } \\
\text { high risk }\end{array}$ \\
\hline Age & Age in years & $\begin{array}{l}46.96(17.19) \\
\mathrm{Up}\end{array}$ & $\begin{array}{l}57.88(13.56) \\
\mathrm{Up}^{* * *}\end{array}$ & $\begin{array}{l}46.58(17.13) \\
\mathrm{Up}^{* * *}\end{array}$ & $\begin{array}{l}57.56(13.88) \\
\mathrm{Up}^{* * *}\end{array}$ & $\begin{array}{l}41.83(17.28) \\
\text { Down*** }\end{array}$ & $\begin{array}{l}58.94(12.35) \\
-\end{array}$ & $\begin{array}{l}52.76(15.37) \\
\mathrm{Up}^{* * *}\end{array}$ & $\begin{array}{l}59.98(11.18) \\
-\end{array}$ \\
\hline Share of men & Dummy variable: 1 if male; 0 otherwise & $0.41(0.49)$ & $0.57(0.50)$ & $\begin{array}{l}0.46(0.50) \\
\text { Down* }\end{array}$ & $0.58(0.49)$ & $\begin{array}{l}0.27(0.44) \\
\text { Down*** }\end{array}$ & $0.55(0.50)$ & $0.44(0.50)$ & $0.54(0.50)$ \\
\hline $\begin{array}{l}\text { Share of Maori / } \\
\text { Pacific Peoples }\end{array}$ & $\begin{array}{l}\text { Dummy variable: } 1 \text { if Maori or Pacific } \\
\text { Peoples; } 0 \text { otherwise }\end{array}$ & $\begin{array}{l}0.25(0.44) \\
\mathrm{Up}^{* * *}\end{array}$ & $\begin{array}{l}0.25(0.43) \\
\mathrm{Up}\end{array}$ & $\begin{array}{l}0.26(0.44) \\
\mathrm{Up}\end{array}$ & $\begin{array}{l}0.26(0.44) \\
\mathrm{Up}^{* *}\end{array}$ & $\begin{array}{l}0.31(0.46) \\
\mathrm{Up}^{* *}\end{array}$ & $\begin{array}{l}0.21(0.40) \\
-\end{array}$ & $\begin{array}{l}0.17(0.38) \\
\mathrm{Up} * * *\end{array}$ & $\begin{array}{l}0.17(0.37) \\
-\end{array}$ \\
\hline Share of Asian & Dummy variable: 1 if Asian; 0 otherwise & $\begin{array}{l}0.06(0.24) \\
\mathrm{Up}^{* * *}\end{array}$ & $\begin{array}{l}0.05(0.22) \\
-\end{array}$ & $\begin{array}{l}0.06(0.24) \\
\mathrm{Up}\end{array}$ & $\begin{array}{l}0.05(0.22) \\
-\end{array}$ & $\begin{array}{l}0.07(0.25) \\
\mathrm{Up}\end{array}$ & $\begin{array}{l}0.03(0.18) \\
-\end{array}$ & $\begin{array}{l}0.05(0.22) \\
\mathrm{Up}^{* * *}\end{array}$ & $\begin{array}{l}0.04(0.19) \\
-\end{array}$ \\
\hline $\begin{array}{l}\text { Share of NZ } \\
\text { European }\end{array}$ & $\begin{array}{l}\text { Dummy variable: } 1 \text { if NZ European; } 0 \\
\text { otherwise }\end{array}$ & $\begin{array}{l}0.65(0.48) \\
\mathrm{Up}^{* * *}\end{array}$ & $\begin{array}{l}0.67(0.47) \\
-\end{array}$ & $\begin{array}{l}0.64(0.48) \\
\mathrm{Up}^{* * *}\end{array}$ & $\begin{array}{l}0.66(0.48) \\
-\end{array}$ & $\begin{array}{l}0.59(0.49) \\
-\end{array}$ & $\begin{array}{l}0.73(0.45) \\
-\end{array}$ & $\begin{array}{l}0.73(0.44) \\
-\end{array}$ & $\begin{array}{l}0.76(0.43) \\
- \\
\end{array}$ \\
\hline $\begin{array}{l}\text { Share of other } \\
\text { ethnicity }\end{array}$ & $\begin{array}{l}\text { Dummy variable: } 1 \text { if other ethnicity; } 0 \\
\text { otherwise }\end{array}$ & $\begin{array}{l}0.04(0.19) \\
\text { Down*** }\end{array}$ & $\begin{array}{l}0.04(0.18) \\
\text { Down*** }\end{array}$ & $\begin{array}{l}0.04(0.19) \\
\text { Down*** }\end{array}$ & $\begin{array}{l}0.04(0.18) \\
\text { Down*** }\end{array}$ & $\begin{array}{l}0.03(0.17) \\
\text { Down*** }\end{array}$ & $\begin{array}{l}0.04(0.19) \\
-\end{array}$ & $\begin{array}{l}0.04(0.20) \\
\text { Down*** }\end{array}$ & $\begin{array}{l}0.04(0.19) \\
\text { Down } * * *\end{array}$ \\
\hline $\begin{array}{l}\text { Clinical } \\
\text { complexity level }\end{array}$ & $\begin{array}{l}\text { Clinical severity, ordinal scale from } 0 \text { to } 4 \\
\text { where } 0=\text { the least severe, } 4=\text { most severe. }\end{array}$ & $\begin{array}{l}0.66(1.22) \\
\text { Down*** }\end{array}$ & $\begin{array}{l}2.30(1.49) \\
\text { Down** }\end{array}$ & $\begin{array}{l}0.80(1.30) \\
\text { Down*** }\end{array}$ & $\begin{array}{l}2.36(1.48) \\
\text { Down*** }\end{array}$ & $\begin{array}{l}0.68(1.22) \\
\text { Down*** }\end{array}$ & $2.04(1.50)$ & $\begin{array}{l}0.36(0.98) \\
\text { Down*** }\end{array}$ & $\begin{array}{l}1.97(1.50) \\
-\end{array}$ \\
\hline Cost weight & $\begin{array}{l}\text { A non-negative continuous variable designed } \\
\text { to weight a base rate payment. }\end{array}$ & $\begin{array}{l}0.87(1.58) \\
\text { Down*** }\end{array}$ & $\begin{array}{l}2.10(3.07) \\
\text { Down*** }\end{array}$ & $\begin{array}{l}0.81(1.49) \\
\text { Down*** }\end{array}$ & $\begin{array}{l}2.11(2.99) \\
\text { Down*** }\end{array}$ & $\begin{array}{l}0.74(1.83) \\
\text { Down*** }\end{array}$ & $\begin{array}{l}1.78(3.62) \\
-\end{array}$ & $\begin{array}{l}1.10(1.45) \\
-\end{array}$ & $\begin{array}{l}2.67(2.82) \\
-\end{array}$ \\
\hline $\begin{array}{l}\text { Hours mechanical } \\
\text { ventilation }\end{array}$ & $\begin{array}{l}\text { Hours on mechanical ventilation while the } \\
\text { patient was in the Intensive Care Unit (ICU). }\end{array}$ & $\begin{array}{ll}1.0 & (19.71) \\
- & \end{array}$ & $\begin{array}{l}15.29(62.54) \\
-\end{array}$ & $\begin{array}{l}1.61(22.92) \\
-\end{array}$ & $\begin{array}{l}17.19(66.55) \\
\text { Down* }\end{array}$ & $0.39(18.34)$ & $\begin{array}{l}4.92(27.05) \\
-\end{array}$ & $\begin{array}{l}0.62(14.33) \\
\text { Down* }\end{array}$ & $5.77(42.73)$ \\
\hline $\begin{array}{l}\text { Share of operative } \\
\text { cases }\end{array}$ & $\begin{array}{l}\text { Dummy variable: } 1 \text { if event has any operative } \\
\text { procedure codes recorded; } 0 \text { otherwise }\end{array}$ & $\begin{array}{l}0.64(0.48) \\
-\end{array}$ & $\begin{array}{l}0.76(0.43) \\
\mathrm{Up}^{* * *}\end{array}$ & $\begin{array}{l}0.41(0.49) \\
\mathrm{Up}^{* * *}\end{array}$ & $\begin{array}{l}0.75(0.44) \\
\mathrm{Up}^{* * *}\end{array}$ & $\begin{array}{l}0.81(0.40) \\
\text { Down*** }\end{array}$ & $\begin{array}{l}0.78(0.42) \\
-\end{array}$ & $\begin{array}{l}0.96(0.21) \\
\mathrm{Up} * * *\end{array}$ & $0.95(0.22)$ \\
\hline $\begin{array}{l}\text { Excess length of } \\
\text { stay }\end{array}$ & $\begin{array}{l}\text { Adjusted length of stay as deviation of the } \\
\text { individual from the average length of stay by } \\
\text { diagnosis and district health board. }\end{array}$ & $\begin{array}{l}5 e-10(6.76) \\
\text { Down*** }\end{array}$ & $\begin{array}{l}\text { 1e-09 (27.86) } \\
\text { Down** }\end{array}$ & $\begin{array}{l}0.13(5.73) \\
\text { Down*** }\end{array}$ & $\begin{array}{l}-0.13(7.83) \\
\text { Down*** }\end{array}$ & $\begin{array}{l}-0.02(10.36) \\
\text { Down*** }\end{array}$ & $\begin{array}{l}1.15(75.20) \\
-\end{array}$ & $\begin{array}{l}-0.25(3.48) \\
\text { Down*** }\end{array}$ & $\begin{array}{l}-0.77(6.21) \\
-\end{array}$ \\
\hline Death & $\begin{array}{l}\text { Dummy variable: } 1 \text { if the event ended with } \\
\text { the death of the patient; } 0 \text { otherwise }\end{array}$ & $\begin{array}{l}0.01(0.07) \\
\text { Down*** } \\
\end{array}$ & $\begin{array}{l}0.16(0.37) \\
-\end{array}$ & $\begin{array}{l}0.01(0.09) \\
\text { Down*** }\end{array}$ & $\begin{array}{l}0.18(0.39) \\
-\end{array}$ & $\begin{array}{l}0.003(0.06) \\
-\end{array}$ & $\begin{array}{l}0.12(0.33) \\
-\end{array}$ & $\begin{array}{l}0.001(0.03) \\
\text { Down*** }\end{array}$ & $\begin{array}{l}0.01(0.12) \\
-\end{array}$ \\
\hline $\begin{array}{l}\text { Emergency } \\
\text { readmission }\end{array}$ & $\begin{array}{l}\text { Dummy variable: } 1 \text { if acute readmission up to } \\
30 \text { days after discharge; } 0 \text { otherwise }\end{array}$ & $\begin{array}{l}0.05(0.21) \\
\mathrm{Up}\end{array}$ & $\begin{array}{l}0.08(0.28) \\
\mathrm{Up} * * *\end{array}$ & $\begin{array}{l}0.06(0.24) \\
\mathrm{Up} * * *\end{array}$ & $\begin{array}{l}0.09(0.28) \\
\mathrm{Up}^{* * *}\end{array}$ & $\begin{array}{l}0.02(0.18) \\
\mathrm{Up}^{* * *}\end{array}$ & $\begin{array}{l}0.08(0.27) \\
\mathrm{Up} * * *\end{array}$ & $\begin{array}{l}0.03(0.17) \\
\mathrm{Up}^{* * *}\end{array}$ & $\begin{array}{l}0.07(0.25) \\
\mathrm{Up}^{*}\end{array}$ \\
\hline Number of events & & $2,667,702$ & 31,751 & $1,367,089$ & 25,796 & 644,593 & 4,064 & 656,020 & 1,891 \\
\hline
\end{tabular}

Note: Standard deviations in parentheses.

A significant increase; decrease; no significant change between 2007 and 2011 is denoted with 'Up'; 'Down'; and '-'. ; ***, ** and * indicate statistical significance at the 1, 5, and 10 percent levels respectively. 
Table 2: Predicted demand $-\mathbf{R}$ squared

\begin{tabular}{lll} 
Regional / DHB sub-samples & Without lags & With lags \\
\hline Auckland & 0.402 & 0.864 \\
Bay of Plenty & $0.075-0.148$ & $0.724-0.734$ \\
Canterbury & $0.217-0.290$ & $0.806-0.892$ \\
Capital and Coast & 0.320 & 0.809 \\
Counties Manukau & $0.175-0.427$ & $0.764-0.811$ \\
Hawke's Bay & 0.182 & 0.681 \\
Hutt Valley & 0.146 & 0.852 \\
Lakes / Rotorua & 0.161 & 0.604 \\
Mid Central & 0.197 & 0.725 \\
Nelson Marlborough & $0.144-0.321$ & $0.514-0.620$ \\
Northland & $0.021-0.236$ & $0.325-0.660$ \\
Otago and Southland & $0.137-0.287$ & $0.614-0.785$ \\
South Canterbury & 0.150 & 0.619 \\
Tarawhiti & 0.161 & 0.584 \\
Taranaki & 0.222 & 0.683 \\
Waikato & $0.150-0.381$ & $0.628-0.822$ \\
Wairarapa & 0.156 & 0.544 \\
Waitemata & $0.122-0.196$ & $0.642-0.747$ \\
West Coast & 0.085 & 0.595 \\
Whanganui & 0.106 & 0.573 \\
\hline Note: There are 20 DHBs and 29 major facilities. In cases where a range for R squared is provided, rather \\
than a solitary figure, this implies multiple facilities within the DHB.
\end{tabular}


Table 3 - Distribution of actual and unexpected demand in NZ hospitals

\begin{tabular}{|c|c|c|c|c|c|c|c|c|c|}
\hline Demand & Mean & $\begin{array}{l}\text { Standard } \\
\text { deviation }\end{array}$ & $5^{\text {th }}$ & $10^{\text {th }}$ & $25^{\text {th }}$ & $\begin{array}{c}\text { Percentil } \\
50^{\text {th }}\end{array}$ & $75^{\text {th }}$ & $90^{\text {th }}$ & $95^{\text {th }}$ \\
\hline \multicolumn{10}{|c|}{ Panel A: Full sample 2007 - 2011} \\
\hline Actual & 1 & 0.190 & 0.710 & 0.792 & 0.903 & 1.001 & 1.093 & 1.199 & 1.294 \\
\hline Unexpected & 1 & 0.166 & 0.812 & 0.869 & 0.938 & 0.992 & 1.046 & 1.119 & 1.191 \\
\hline \multicolumn{10}{|c|}{ Panel B: Regional / DHB sub-samples } \\
\hline Unexpected: & & & & & & & & & \\
\hline Auckland & 1 & 0.036 & 0.946 & 0.958 & 0.977 & 1.000 & 1.022 & 1.043 & 1.055 \\
\hline Bay of Plenty & 1 & 0.065 & 0.903 & 0.922 & 0.955 & 0.994 & 1.041 & 1.085 & 1.108 \\
\hline Canterbury & 1 & 0.069 & 0.894 & 0.921 & 0.959 & 0.996 & 1.036 & 1.081 & 1.110 \\
\hline Capital and Coast & 1 & 0.070 & 0.893 & 0.914 & 0.951 & 0.997 & 1.041 & 1.088 & 1.117 \\
\hline Counties Manukau & 1 & 0.280 & 0.769 & 0.825 & 0.939 & 0.991 & 1.032 & 1.111 & 1.230 \\
\hline Hawke’s Bay & 1 & 0.089 & 0.868 & 0.895 & 0.941 & 0.993 & 1.048 & 1.112 & 1.148 \\
\hline Hutt Valley & 1 & 0.058 & 0.910 & 0.929 & 0.960 & 0.996 & 1.039 & 1.074 & 1.096 \\
\hline Lakes / Rotorua & 1 & 0.137 & 0.808 & 0.846 & 0.909 & 0.986 & 1.072 & 1.168 & 1.249 \\
\hline Mid Central & 1 & 0.369 & 0.602 & 0.676 & 0.818 & 0.960 & 1.075 & 1.307 & 1.565 \\
\hline Nelson Marlborough & 1 & 0.080 & 0.881 & 0.907 & 0.951 & 0.994 & 1.044 & 1.102 & 1.138 \\
\hline Northland & 1 & 0.108 & 0.844 & 0.872 & 0.922 & 0.990 & 1.063 & 1.140 & 1.192 \\
\hline Otago and Southland & 1 & 0.114 & 0.815 & 0.869 & 0.949 & 0.995 & 1.042 & 1.121 & 1.199 \\
\hline South Canterbury & 1 & 0.120 & 0.829 & 0.858 & 0.917 & 0.991 & 1.062 & 1.156 & 1.219 \\
\hline Tarawhiti & 1 & 0.086 & 0.877 & 0.900 & 0.944 & 0.992 & 1.049 & 1.108 & 1.149 \\
\hline Taranaki & 1 & 0.151 & 0.789 & 0.822 & 0.893 & 0.982 & 1.084 & 1.197 & 1.275 \\
\hline Waikato & 1 & 0.052 & 0.921 & 0.936 & 0.966 & 0.997 & 1.031 & 1.065 & 1.087 \\
\hline Wairarapa & 1 & 0.077 & 0.883 & 0.909 & 0.954 & 0.996 & 1.041 & 1.088 & 1.122 \\
\hline Waitemata & 1 & 0.096 & 0.855 & 0.888 & 0.944 & 0.995 & 1.047 & 1.111 & 1.161 \\
\hline West Coast & 1 & 0.173 & 0.769 & 0.814 & 0.881 & 0.974 & 1.092 & 1.217 & 1.314 \\
\hline Whanganui & 1 & 0.106 & 0.847 & 0.874 & 0.924 & 0.992 & 1.067 & 1.132 & 1.182 \\
\hline
\end{tabular}

Panel C: Yearly sub-samples

\begin{tabular}{llllllllll}
\hline Unexpected 2007* & - & - & - & - & - & - & - & - & - \\
Unexpected 2008 & 1 & 0.194 & 0.804 & 0.867 & 0.938 & 0.991 & 1.044 & 1.116 & 1.185 \\
Unexpected 2009 & 1 & 0.149 & 0.823 & 0.875 & 0.940 & 0.992 & 1.046 & 1.119 & 1.187 \\
Unexpected 2010 & 1 & 0.159 & 0.810 & 0.865 & 0.936 & 0.993 & 1.047 & 1.121 & 1.202 \\
Unexpected 2011 & 1 & 0.159 & 0.813 & 0.869 & 0.937 & 0.993 & 1.049 & 1.121 & 1.193 \\
\hline
\end{tabular}

Note: * Cannot predict expected patient count in 2007 due to lack of information on demand in 2006. 


\begin{tabular}{|c|c|c|c|c|c|c|c|c|c|}
\hline \multirow{2}{*}{$u_{j b}$} & \multirow[t]{2}{*}{ Mean } & \multirow{2}{*}{$\begin{array}{l}\text { Standard } \\
\text { deviation }\end{array}$} & \multicolumn{7}{|c|}{ Percentile } \\
\hline & & & $5^{\text {th }}$ & $10^{\text {th }}$ & $25^{\text {th }}$ & $50^{\text {th }}$ & $75^{\text {th }}$ & $90^{\text {th }}$ & $95^{\text {th }}$ \\
\hline \multicolumn{10}{|c|}{ Full sample $2007-2011$} \\
\hline & 0.049 & 0.053 & -0.0003 & 0.010 & 0.024 & 0.038 & 0.061 & 0.101 & 0.148 \\
\hline \multicolumn{10}{|c|}{ Regional / DHB sub-samples } \\
\hline Auckland & 0.025 & 0.009 & 0.006 & 0.014 & 0.016 & 0.025 & 0.031 & 0.037 & 0.043 \\
\hline Capital Coast & 0.049 & 0.107 & 0.0004 & 0.007 & 0.020 & 0.029 & 0.032 & 0.040 & 0.271 \\
\hline
\end{tabular}


Table 5: Patient outcomes

\section{Panel A: Outcome $=$ Excess length of stay}

\begin{tabular}{|c|c|c|c|c|}
\hline & \multicolumn{2}{|c|}{ Elective admissions } & \multicolumn{2}{|c|}{ Acute admissions } \\
\hline & Low risk & High risk & Low risk & High risk \\
\hline Unexpected demand at hospital level & $-0.213^{* * *}$ & 0.220 & 0.028 & -0.136 \\
\hline Unexpected demand within disease chapter & $-24.629 * * *$ & 10.448 & $-15.826 * * *$ & $-10.758^{* * *}$ \\
\hline $\mathrm{R}$ squared & 0.341 & 0.361 & 0.358 & 0.336 \\
\hline $\mathrm{N}$ & 950,480 & 4,374 & $1,072,349$ & 20,249 \\
\hline
\end{tabular}

\section{Panel B: Outcome $=$ Probability of readmission within 30 days}

Unexpected demand at hospital level

Unexpected demand within disease chapter

Excess length of stay

Pseudo R squared

Elective admissions

\begin{tabular}{cccc} 
Low risk & High risk & Low risk & High risk \\
\hline $0.003^{* *}$ & -0.001 & -0.002 & 0.008 \\
0.012 & $-0.943^{* *}$ & -0.013 & $-0.738^{* * *}$ \\
$-0.0001^{* * *}$ & -0.0008 & $0.0005^{* * *}$ & 0.0003 \\
0.024 & 0.056 & 0.028 & 0.052 \\
949,263 & 4,067 & $1,064,040$ & 16,665
\end{tabular}

\section{$\mathrm{N}$}

Elective admissions

Acute admissions

\begin{tabular}{|c|c|c|c|c|}
\hline & \multicolumn{2}{|c|}{ Elective admissions } & \multicolumn{2}{|c|}{ Acute admissions } \\
\hline & Low risk & High risk & Low risk & High risk \\
\hline Unexpected demand at hospital level & $-1.12 \mathrm{e}-06$ & 0.021 & $-0.0004^{*}$ & - \\
\hline Unexpected demand within disease chapter & $0.001 * * *$ & $-0.515^{* * *}$ & $0.017 * * *$ & - \\
\hline Pseudo R squared & 0.367 & 0.236 & 0.298 & - \\
\hline $\mathrm{N}$ & 931,020 & 4,350 & $1,070,256$ & - \\
\hline
\end{tabular}

Notes: Panel A's results are based on a linear regression, whereas results from Panel B and C are marginal effects estimates from probit models. $* * *, * *$ and * indicate statistical significance at the 1, 5, and 10 percent levels respectively. 
Appendix 1-Distribution of events by DHBs \& regional descriptives

\begin{tabular}{|c|c|c|c|c|c|}
\hline NZ regional DHBs & $\begin{array}{l}\text { Hospital } \\
\text { events }\end{array}$ & $\%$ of sample & Urban (\%) & $\begin{array}{l}\text { Population } \\
\text { size }\end{array}$ & $\begin{array}{c}\text { Proportion } \\
\text { above } \\
\text { median } \\
\text { income }(\%)\end{array}$ \\
\hline Counties Manukau & 331,080 & 12.26 & 93 & 433,086 & 50 \\
\hline Auckland & 317,520 & 11.76 & 99.8 & 404,619 & 54 \\
\hline Canterbury & 277,451 & 10.28 & 84 & 466,407 & 48 \\
\hline Waitemata & 256,547 & 9.5 & 94 & 481,611 & 53 \\
\hline Waikato & 249,973 & 9.26 & 78 & 339,189 & 48 \\
\hline Capital and Coast & 169,688 & 6.29 & 99 & 266,658 & 56 \\
\hline Northland & 160,691 & 5.95 & 51 & 148,440 & 43 \\
\hline Otago and Southland & 151,754 & 5.62 & 77 & 286,224 & 45 \\
\hline Bay of Plenty & 129,437 & 4.79 & 79 & 194,931 & 45 \\
\hline Mid Central & 100,890 & 3.74 & 67 & 158,841 & 45 \\
\hline Hawke's Bay & 98,758 & 3.66 & 87 & 148,248 & 46 \\
\hline Hutt Valley & 80,477 & 2.98 & 98 & 136,101 & 53 \\
\hline Nelson Marlborough & 77,579 & 2.87 & 78 & 130,062 & 46 \\
\hline Taranaki & 70,551 & 2.61 & 77 & 104,277 & 47 \\
\hline Lakes & 68,714 & 2.55 & 81 & 98,319 & 48 \\
\hline Whanganui & 46,993 & 1.74 & 81 & 62,208 & 42 \\
\hline South Canterbury & 38,014 & 1.41 & 50 & 53,877 & 43 \\
\hline Tairawhiti & 31,717 & 1.17 & 71 & 44,463 & 42 \\
\hline Wairarapa & 24,004 & 0.89 & 76 & 38,613 & 45 \\
\hline West Coast & 17,615 & 0.65 & 58 & 31,329 & 42 \\
\hline
\end{tabular}

Total 2,699,453 100

Source: National Minimum Dataset for hospital events.

Urban (\%) sourced from individual DHB reports ranging from 2004 to 2012, and Pool, et al (2009).

Population size and proportion above median income sourced from 2006 census. 
